\title{
Guanine Nucleotide-Binding Protein a Subunit Hypofunction in Children with Short Stature and Disproportionate Shortening of the 4th and 5th Metacarpals
}

\author{
Ioana Monica Inta ${ }^{a}$ Daniela Choukaira Sebastian Bender ${ }^{\text {b, c }}$ Carolin Kneppo $^{a}$ \\ Sabine Knauer-Fischer ${ }^{a}$ Kahina Meyenburg ${ }^{d}$ Boris Ivandic $^{e}$ \\ Stefan M. Pfister ${ }^{b, c}$ Markus Bettendorfa \\ a Division of Paediatric Endocrinology and bepartment of Paediatric Oncology, Haematology \& Immunology, \\ University Children's Hospital Heidelberg, 'Division of Paediatric Neurooncology, German Cancer Research Center \\ (DKFZ), and d Department of Child and Adolescent Psychiatry, and ${ }^{\mathrm{e}}$ Internal Medicine, Department of Medicine III, \\ University of Heidelberg, Heidelberg, Germany
}

\section{Key Words}

Short stature - Metacarpal dysmorphology - Gsa protein . GNAS mutation · Epigenetic analysis

\section{Abstract \\ Background: GNAS encodes the a subunit of the stimulatory $\mathrm{G}$ protein (Gsa). Maternal inherited Gsa mutations cause pseudohypoparathyroidism type la (PHP-la), associated with shortening of the 4th and 5th metacarpals. Aims: Here we investigated the Gsa pathway in short patients with distinct shortening of the 4th and 5th metacarpals. Methods: In 571 children with short stature and 4 patients with PHP-la meta- carpal bone lengths were measured. In identified patients we analysed the Gsa protein function in platelets, performed GNAS sequencing, and epigenetic analysis of four significant differentially methylated regions. Results: In 51 patients $(8.9 \%)$ shortening of the 4 th and 5 th metacarpals was more pronounced than their height deficit. No GNAS coding muta- tions were identified in 20 analysed patients, except in 2 PHP-la patients. Gsa activity was reduced in all PHP-la pa- tients and in $25 \%$ of the analysed patients. No significant methylation changes were identified. Conclusions: Our find-}

ings suggest that patients with short stature and distinct metacarpal bone shortening could be part of the wide variety of PHP/PPHP, therefore it was worthwhile analysing the Gsa protein function and GNAS gene in these patients in order to further elucidate the phenotype and genotype of Gsa dysfunction.

(c) 2014 S. Karger AG, Basel

\section{Introduction}

Infrequently, patients with short stature have shortening of the 4th and 5th metacarpals as is often found in Albright's hereditary osteodystrophy (AHO) [1]. This peculiar phenotype further includes classically short stature, heterotopic ossifications, mental retardation, and obesity with rounded face [1]. In some subjects it is associated with parathormone renal resistance and is known as pseudohypoparathyroidism (PHP) type Ia (OMIM:

I.M.I. and D.C. contributed equally to this work and should therefore be considered as first co-authors.

\section{KARGER}

E-Mail karger@karger.com www.karger.com/hrp
(C) 2014 S. Karger AG, Basel

$1663-2818 / 14 / 0813-0196 \$ 39.50 / 0$
Ioana Monica Inta

Division of Paediatric Endocrinology

University Children's Hospital

Im Neuenheimer Feld 430, DE-69120 Heidelberg (Germany)

E-Mail Ioana.Inta@med.uni-heidelberg.de 
103580) [2-4]. The underlying cause is an inactivating mutation of GNAS [2]. The most well-characterized GNAS product is the $G$ protein $\alpha$ subunit $(G s \alpha)$, which is encoded by exons 1-13 of GNAS. Although Gsa is expressed biallelically in most tissues, in the pituitary, thyroid, gonads, and the proximal renal tubule it is only maternally expressed and paternally silenced by imprinting $[5,6]$. Thus, only maternal transmission of GNAS mutations leads to PHP-Ia with altered Gs-coupled pathway by the indicated hormones [7-10].

PHP-Ib (OMIM: 603233) is associated with a loss of methylation at the GNAS exon A/B (also called 1A). Apart from Gsa, the GNAS locus gives rise to different products through the use of alternative promoters and first exons that splice onto a common set of downstream exons. These additional gene products are oppositely imprinted: extralarge stimulatory Gsa (XLas), NESPas, and A/B are paternally expressed and maternally silenced by methylation, whereas neuroendocrine secretory protein-55 (NESP55) is maternally expressed and paternally silenced [11-14]. Methylation changes in the NESP55, NESPas, and XLas promoter regions have been previously described in patients with a sporadic form of PHP-Ib [15], except for in a few families with additional NESP55 deletions [16].

Interestingly, recent studies reported PHP-Ia patients with no coding mutations in the GNAS gene, which is similar to methylation defects in PHP-Ib patients [17-19]. These data confirm the presence of an overlap between different forms of PHP at the clinical and molecular level.

Considering the complex regulated Gsa pathway, we hypothesized that this pathway is more frequently involved in the aetiology of short stature with disproportionate metacarpal shortening than currently appreciated. Furthermore, we investigated Gs $\alpha$ protein activity in freshly isolated platelets and analysed mutations within the Gsa coding exons and performed epigenetic studies of the GNAS locus.

\section{Patients and Methods}

\section{Patients}

We included 571 patients with short stature (height $<-2$ standard deviation score (SDS)) who presented consecutively between 2003 and 2005 in the paediatric endocrinology outpatient clinic of the University Children's Hospital Heidelberg, Germany, with the following diagnoses, confirmed as recommended by standard national guidelines: idiopathic short statue (ISS), small for gestational age (SGA), growth hormone deficiency (GHD), and Turner syndrome (TS) (fig. 1). Chronological ages, heights, height SDS, weights, and bone ages according to the method of Greulich and Pyle were documented [20-23]. Four patients with PHP-Ia were analysed, serving as positive

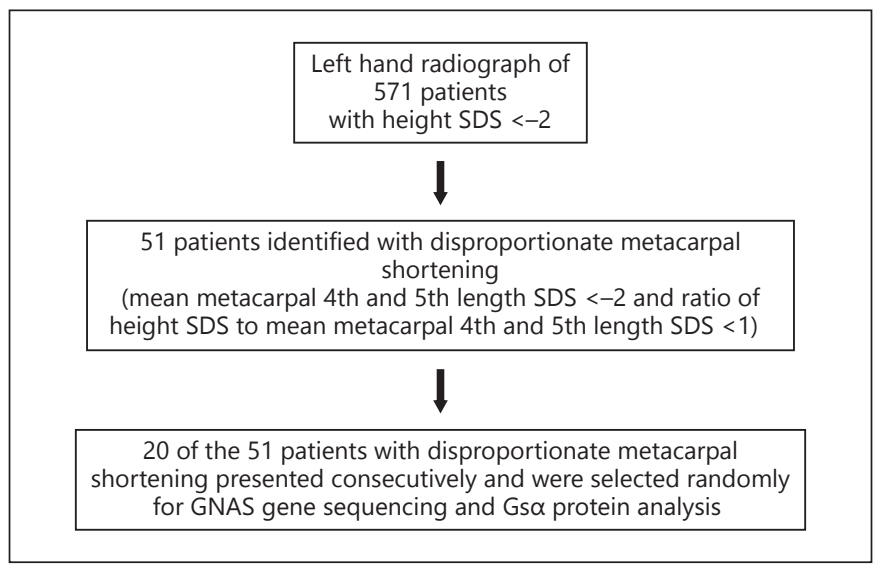

Fig. 1. Participant profile.

controls. Radiographs of the left hand previously made at routine controls to evaluate bone age were available for all 575 patients including the 4 patients with PHP-Ia. The length of metacarpals (1-5) and phalanges (distal, medial, proximal) were measured and expressed as SDS for bone age using references of healthy children [24].

Patients with significant shortening of the 4 th and 5th metacarpals in relation to their height (mean 4th and 5th metacarpal length SDS $<-2$, height SDS $<-2$, and ratio of height SDS to mean 4 th and 5 th metacarpal length SDS $\leq 1$ ) were selected. From these selected patients, 20 were presented randomly and consecutively in our outpatient department from June to December 2006 and agreed to further participation in this study. Blood samples were collected in order to analyse Gsa protein function, for GNAS sequencing, and epigenetic analysis (fig. 1). Additionally, 4 healthy children with normal stature and without disproportionate shortening of the 4 th and 5th metacarpals were included, serving as negative controls analysing Gsa protein activity.

The study protocol was approved by the institutional review board, and Gsa protein activity, GNAS gene, and epigenetic analysis were performed after written consent was obtained.

\section{Gs $\alpha$ Protein Activity}

In order to evaluate Gsa hypofunction, measurement of platelet Gsa function by collagen-induced platelet aggregation in the presence of Gsa-coupled receptor agonist (prostaglandin $\mathrm{E}_{1}$ ) was performed in freshly isolated platelets as previously described [25, 26]. Additionally, Gsa protein activity was measured in 4 patients suffering from PHP-Ia, serving as positive controls.

\section{GNAS Gene Sequencing}

Genomic DNA was extracted from whole blood samples using a QIAamp Blood Kit according to the manufacturer's protocol (Qiagen, Hilden, Germany). The GNAS gene (exons 1-13) was then amplified by PCR using specific primers as previously described [7, 27]. PCR products were purified using a QIAquick PCR Purification Kit (Qiagen). Sequencing of the PCR products using both sense and antisense primers was performed using an ABI PRISM Big Dye Terminator Kit following the protocol of the supplier (PE Applied Biosystems, Forster City, Calif., USA). Sequencing products were analysed on an ABI Prism 310 sequencer (PE Applied Biosystems). 
Methylation Analysis of the GNAS Locus by Methyl-DNA

Immunoprecipitation

Differential methylation analysis of DMRs within the GNAS gene A/B, NESP55, NESPas, and XLas was performed in a group of patients as described before [28]. Briefly, $5.5 \mu \mathrm{g}$ of DNA was sonicated to produce a random fragment size of $500 \mathrm{bp}$. After denaturation for $10 \mathrm{~min}$ at $95^{\circ} \mathrm{C}$, immunoprecipitation was performed overnight at $4^{\circ} \mathrm{C}$ with $10 \mu \mathrm{l}$ monoclonal antibody against 5-methylcytidine (Eurogentec, Cologne, Germany) in a final volume of $500 \mu \mathrm{I}$ IP buffer (10 mM sodium phosphate, pH 7.0, $140 \mathrm{mM}$ $\mathrm{NaCl}, 0.05 \%$ Triton X-100). The reaction was incubated with $30 \mu \mathrm{l}$ of blocked Dynabeads M-280 sheep antibody to mouse IgG (Dynal Biotech, Hamburg, Germany) for $2 \mathrm{~h}$ at room temperature and washed three times with $700 \mu \mathrm{l}$ of IP buffer. After incubation with proteinase $\mathrm{K}$ for $3 \mathrm{~h}$ at $55^{\circ} \mathrm{C}$, methylated DNA was recovered by phenol-chloroform extraction followed by ethanol precipitation.

PCR primers for the amplification of the four different GNAS DMRs were previously described [29]. The primers were adapted for methyl-DNA immunoprecipitation (MeDIP) analysis as following: A/B DMR forward 5' -ATGGCCATGAAGCTCAAAGC-3' and reverse $5^{\prime}$-GCCGTCTTCTTCTCGCTCT-3; NESPas DMR forward $5^{\prime}$-GGGCTAAAGGAGCTGACTGA-3 and reverse $5^{\prime}$-T AGGGTGGTTTCGAGACTGG-3' ${ }^{\prime}$; XLas DMR forward $5^{\prime}$-GAC GACACTCCCGTCAACAT- $3^{\prime}$ and reverse $5^{\prime}$-TTCCATCTCTG CTGCTTCCT-3'; NESP55 DMR forward $5^{\prime}$-CTTCCAAAAAG GGACCCATC- $3^{\prime}$ and reverse $5^{\prime}$-TGGGCAACTAACCTGAAT CC- $3^{\prime}$. Additionally the $\mathrm{CpG}$ island up- and downstream of GNAS$\mathrm{AB}$ was analysed using the following primers: $\mathrm{AB} \_1$ forward $5^{\prime}$-CCCCCAATTCTCTCTCTTTTC- $3^{\prime}$ and reverse $5^{\prime}$-TGGCA GGAGTCTGTTTACCC-3'; AB_2 forward $5^{\prime}$-TTCCTTTTCG GTTGCTCTGT- $3^{\prime}$ and reverse $5^{\prime}$-AGAGCCAGAGAGCAGG AGTG- ${ }^{\prime}$, and AB_3 forward $5^{\prime}$-TGCCTCGGGAACAGTAAG AC- $3^{\prime}$ and reverse $5^{\prime}$-GTCCTTCTGCAGCTGCTTCT- $3^{\prime}$.

Real-time PCR on MeDIP DNA was carried out in triplicate using an ABI PRISM 7700 PCR System (Applied Biosystems) and AbBsolute SYBR Green ROX Mix (ABgene, Lafayette, Colo., USA).

\section{Statistical Analysis}

Statistical analysis was performed using Kruskal-Wallis and Scheffé's test (StatView; SAS Institute, Cary, N.C., USA). A p value $<0.05$ was considered significant.

\section{Results}

A total number of 571 patients (301 males, 270 females) with different aetiologies of short stature were identified (fig. 1). Significant differences regarding chronological age, bone age, and height SDS were noticed between different groups of short stature patients, showing that patients with GHD and SGA were significantly younger compared to patients with ISS (data not shown). Concerning height SDS, patients with ISS had a less severe height SDS deficit compared to patients with SGA, TS, and GHD, but comparable to that observed in patients with PHP-Ia (data not shown). Further, no typical signs of AHO (as

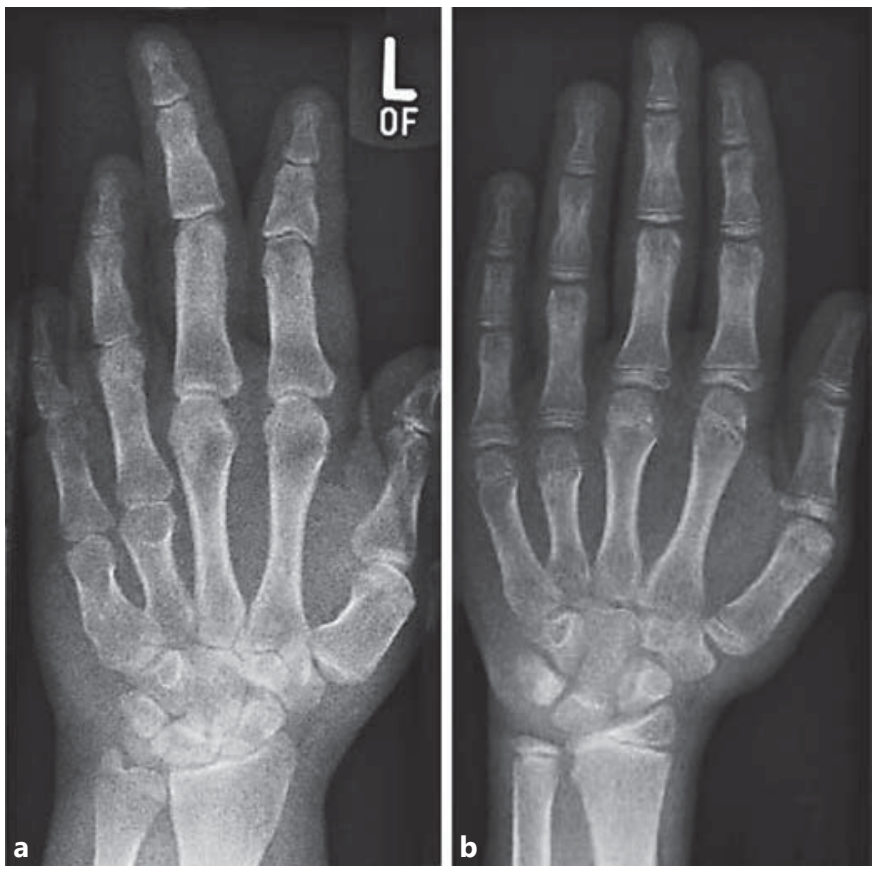

Fig. 2. Radiographs of the left hand of patients with (a) PHP-Ia (ratio of height SDS to mean 4th and 5th metacarpal length SDS 0.31 ) and (b) short stature (ratio of height SDS to mean 4th and 5th metacarpal length SDS 0.79).

round face, obesity, subcutaneous calcification, or intellectual disabilities) or abnormalities in the serum calcium or phosphate metabolism were documented. No significant differences concerning length of the metacarpal bones and their ratio to height SDS were noticed between these groups (data not shown). Measurements of the metacarpal bones in all patients with short stature showed a mean reduction of the length of the 4 th and 5 th metacarpals of $-1.16 \pm 1.4$ SDS and a mean height SDS of $-3.29 \pm$ 0.91 . When considering all analysed patients as a homogeneous population of patients with short stature, the loss in the length of metacarpal bones could be globally explained by the loss in height SDS. Therefore, we selected a subgroup of patients who presented a more pronounced loss of the length of 4 th and 5 th metacarpal bones in relation to their height. These patients were considered as presenting a disproportionate metacarpal shortening (mean 4 th and 5th metacarpal length SDS $<-2$, height SDS $<-2$, and ratio of height SDS to mean 4th and 5th metacarpal length SDS $\leq 1$ ) and were further analysed (fig. 1). Representative radiographs of a patient with PHP-Ia (fig. 2a) and a patient with short stature and a ratio of height SDS to mean 4 th and 5th metacarpal length SDS $\leq 1$ are shown (fig. 2b). Meeting inclusion criteria of disproportionate 
Table 1. Auxological data of patients with short stature and short metacarpals in relation to their height

\begin{tabular}{lccrrrrr}
\hline Patients & Male & Female & CA, years & BA, years & Height SDS & $\begin{array}{l}\text { Mean metacarpal 4th } \\
\text { and 5th length SDS }\end{array}$ & $\begin{array}{l}\text { Ratio of height SDS to } \\
\text { mean metacarpal 4th } \\
\text { and 5th length SDS }\end{array}$ \\
\hline ISS (n= 36) & 22 & 14 & $11.2 \pm 5.4$ & $11.1 \pm 5.8$ & $-2.6 \pm 0.5$ & $-3.2 \pm 0.8$ & $0.8 \pm 0.1$ \\
SGA (n =5) & 2 & 3 & $12.3 \pm 3.8$ & $12.1 \pm 3.5$ & $-2.8 \pm 0.4$ & $-3.1 \pm 0.4$ & $0.9 \pm 0.1$ \\
TS (n = 4) & & 4 & $9.3 \pm 3.1$ & $9.3 \pm 3.9$ & $-2.8 \pm 0.4$ & $-3.6 \pm 0.4$ & $0.8 \pm 0.2$ \\
GHD (n=6) & 3 & 3 & $6.3 \pm 3.7$ & $6.1 \pm 5.2$ & $-3.1 \pm 0.9$ & $-3.9 \pm 1.2$ & $0.8 \pm 0.2$ \\
PHP-Ia (n=4) & 2 & 2 & $12.3 \pm 6.4$ & n.d. & $-2.8 \pm 1.5$ & $-6.4 \pm 2.2$ & $0.4 \pm 0.1$ \\
\hline
\end{tabular}

$\mathrm{CA}=$ Chronological age; $\mathrm{BA}=$ bone age (determined according to the method of Greulich and Pyle); n.d. = not done. No statistical differences were noted as analysed by Kruskal-Wallis test between different diagnoses of short stature patients regarding age, bone age, height SDS, length of metacarpal bones, and their ratio to height SDS.

metacarpal shortening, 51 patients with short stature (27 males, 24 females) were identified with the following diagnosis: ISS $(\mathrm{n}=36)$, SGA $(\mathrm{n}=5)$, TS $(\mathrm{n}=4)$, and GHD $(\mathrm{n}=$ 6) (fig. 1; table 1). This represents $8.9 \%$ of all analysed patients. Their auxological data are presented in table 1 . No significant difference was observed between these groups comparing chronological ages, bone ages, height SDS, means of the 4th and 5th metacarpal length SDS, and ratios of height SDS to mean 4th and 5th metacarpal length SDS $\leq 1$.

GNAS gene sequencing and Gsa protein analysis were performed (fig. 1) in 20 randomly selected patients and in 4 patients with PHP-Ia who presented consecutively in our outpatient department with short stature and ratios of height SDS to a mean 4th and 5th metacarpal length of SDS $\leq 1$. Their auxological data are presented in table 2: ISS $(\mathrm{n}=13)$, SGA $(\mathrm{n}=1)$, GHD $(\mathrm{n}=3)$, TS $(\mathrm{n}=$ $3)$, and PHP-Ia $(\mathrm{n}=4)$. Chronological age varied from 2.0 to 17.7 years, and bone age from 1.5 to 17.0 years (table 2). No significant differences concerning chronological age and bone age between the groups were noticed. With the exception of 1 patient (No. 21) with PHPIa (height SDS -1.14), all patients presented with a height SDS $<-2$ (range -2.2 to -4.6 ) and a mean of the 4 th and 5 th metacarpal length SDS $<-2$ (range -2.2 to -8.7 ), without any significant differences between the distinct groups ( $\mathrm{p}=0.48$ for height SDS; $\mathrm{p}=0.41$ for mean metacarpal length SDS).

Mutations in the GNAS coding exons were identified in 2 out of 4 PHP-Ia patients. Patient No. 21 harboured a mutation in exon 5 in codon 115, a nucleotide sequence insertion from CCC $\rightarrow$ CTCC, causing a frameshift mutation with a premature stop codon at position 139 and patient No. 22 presented a 4-bp deletion $\triangle$ GACT in codon
189/190 with a stop codon at position 202 in exon 7 . No further mutations in the GNAS coding exons were detected in this cohort of patients with short stature and disproportionate metacarpal shortening (table 2). In patient No. 3, two silent mutations, one in exon 7, codon 185 $(\mathrm{ATC} \rightarrow$ ATT) and onein exon 13, codon 371 (AAC $\rightarrow$ AAT) were present. In patient No. 9 we identified one base substitution from $\mathrm{G} \rightarrow \mathrm{A}$ in intron 7 .

Further we investigated in our selected patients with disproportionate metacarpal shortening the Gsa protein activity in freshly isolated platelets. As expected, all examined patients with PHP-Ia presented a reduction of Gsa protein activity (fig. 3). Interestingly, 4 out of 16 investigated patients with short stature and disproportionate metacarpal shortening (representing 25\%) also showed a reduction of the Gsa function comparable to that of patients with PHP-Ia (fig. 3). This group included 2 patients with ISS, 1 with TS, and 1 with GHD. Gsa activation was also measured in the 4 healthy patients serving as negative controls (fig. 3) and showed normal activity. By this analysis, we identified a group of patients with short stature and significant short 4th and 5th metacarpals, presenting a reduction in the Gsa protein activity, without coding mutations in the GNAS exons.

Next we decided to analyse DMRs within the GNAS gene of the 4 patients with short stature and disproportionate metacarpal shortening, presenting Gsa hypofunction and of the 4 negative controls. Compared to our controls, a tendency towards reduced methylation was observed in our short stature patients, without reaching statistical significance (data not shown). Furthermore, knowing that in PHP-Ib patients the reduced Gsa expression in the proximal renal tubule is due mainly to methylation deficiencies in the A/B locus, we analysed 
Table 2. Auxological data and GNAS analysis of patients with short stature and metacarpal dysmorphology and patients with PHP-Ia

\begin{tabular}{|c|c|c|c|c|c|c|c|c|c|c|}
\hline 2 & ISS & 15.1 & 15 & -2.2 & no & -2.2 & 1.0 & no mutation & TT & reduced \\
\hline 3 & ISS & 2.2 & 1.5 & -4.6 & no & -5.0 & 0.9 & $\begin{array}{l}\text { ATC } \rightarrow \text { ATT, exon } 7 \\
\text { and AAC } \rightarrow \text { AAT, exon } \\
13 \text {, silent mutation }\end{array}$ & TT & normal \\
\hline 4 & ISS & 2.4 & 2.5 & -2.7 & no & -2.9 & 1.0 & no mutation & $\mathrm{TT}$ & normal \\
\hline 5 & ISS & 13.1 & 11.5 & -2.7 & no & -2.8 & 1.0 & no mutation & $\mathrm{CC}$ & normal \\
\hline 6 & ISS & 17.7 & 17.0 & -2.8 & no & -3.2 & 0.9 & no mutation & $\mathrm{CC}$ & normal \\
\hline 7 & ISS & 2.4 & 2.0 & -3.0 & no & -3.8 & 0.8 & no mutation & $\mathrm{TT}$ & n.d. \\
\hline 8 & ISS & 14.8 & 14 & -3.44 & no & -3.6 & 1.0 & no mutation & $\mathrm{TC}$ & reduced \\
\hline 9 & ISS & 10.1 & 9 & -2.6 & no & -5.0 & 0.5 & intron 7,1 bp $G \rightarrow A$ & $\mathrm{TC}$ & n.d. \\
\hline 13 & ISS & 12.5 & 11 & -2.8 & no & -3.1 & 0.9 & no mutation & TC & normal \\
\hline 14 & TS & 11.2 & 11.0 & -3.2 & yes & -3.4 & 1.0 & no mutation & $\mathrm{TC}$ & normal \\
\hline 15 & TS & 5.3 & 4 & -2.9 & yes & -3.3 & 0.9 & no mutation & $\mathrm{CC}$ & reduced \\
\hline 16 & TS & 8.6 & 9 & -2.8 & yes & -4.3 & 0.7 & no mutation & $\mathrm{CC}$ & normal \\
\hline 17 & SGA & 10.5 & 10.5 & -2.9 & no & -3.0 & 1.0 & no mutation & $\mathrm{TC}$ & normal \\
\hline 18 & GHD & 2.1 & 1 & -2.7 & yes & -3.2 & 0.9 & no mutation & $\mathrm{TC}$ & normal \\
\hline 19 & GHD & 7.2 & 6 & -2.5 & yes & -2.7 & 0.9 & no mutation & $\mathrm{TC}$ & reduced \\
\hline 20 & GHD & 5.5 & 4 & -3 & yes & -3.2 & 1.0 & no mutation & $\mathrm{TC}$ & normal \\
\hline 21 & PHP-Ia & 8.7 & 8.5 & -1.14 & no & -3.7 & 0.3 & $\begin{array}{l}\text { CCC } \rightarrow \text { CTCC, exon } 5 \text {, } \\
\text { codon } 115\end{array}$ & TT & reduced \\
\hline 22 & PHP-Ia & 2.0 & n.d. & -2.26 & no & -5.7 & 0.4 & $\begin{array}{l}4 \text { bp deletion }(\triangle \mathrm{GACT}) \\
\text { exon } 7 \text {, codon } 189 / 190\end{array}$ & TT & reduced \\
\hline
\end{tabular}

$\mathrm{CA}=$ Chronological age; $\mathrm{BA}=$ bone age (determined according to the method of Greulich and Pyle); $\mathrm{GH}=$ growth hormone treatment; n.d. = not done. No significant differences regarding age and bone age between the groups with different diagnoses were noticed as analysed by Kruskal-Wallis test $(\mathrm{p}=0.23$, respectively $\mathrm{p}=0.2)$.

the CpG island upstream of the GNAS-A/B locus in more detail. Our study showed that a region further upstream of the GNAS-A/B DMR within this CpG island is methylated in all investigated patients, whereas no methylation was detected within the CpG island further downstream of the GNAS A/B DMR (data not shown).

\section{Discussion}

In this study we identified a phenotype consisting of short stature associated with disproportionate metacarpal shortening (ratios of height SDS to mean 4th and 5th metacarpal length SDS $\leq 1$ ). This distinct phenotype was present in $8.9 \%$ of a large cohort of patients with short stature $(n=571)$. It is not uncommon that short stature is associated with dysmorphology of the metacarpal bones as is the case in patients with dyschondrosteosis, TS, hypochondroplasia, or brachydactyly type E [30,31]. We assume that the complex regulated Gsa pathway is more frequently involved in the aetiology of short stature with disproportionate metacarpal shortening than currently appreciated. Indeed, we could demonstrate that in 4 of 16 analysed patients with disproportionate metacarpal shortening a reduction of Gsa protein activity was present in platelets. Because mutations of GNAS were detected in patients with PHP-Ia and PPHP who presenting typically $\mathrm{AHO}$, we screened our cohort for mutations 
Fig. 3. Platelet Gsa aggregation-inhibition test. Dose-dependent inhibition of collagen-induced platelet aggregation $(2 \mu \mathrm{g} / \mathrm{ml})$ by the indicated concentrations of the Gsacoupled receptor agonist prostaglandin $\mathrm{E}_{1}$ (ng/ml) for 4 control patients, 4 patients with PHP-Ia, and the 4 identified patients with short stature and distinct shortening of the 4 th and 5 th metacarpals.

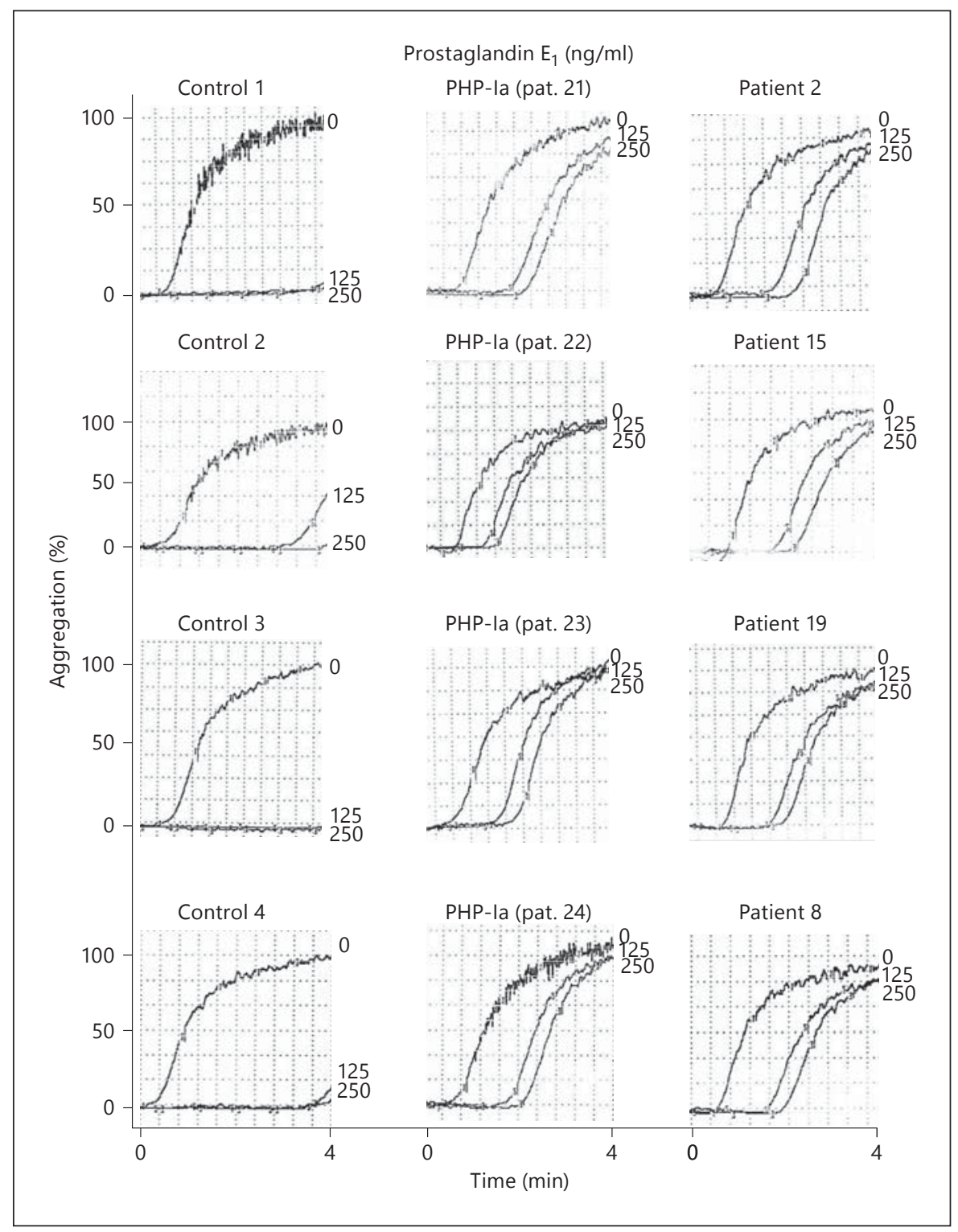

within the GNAS gene [32]. However, no loss-of-function mutations in the GNAS exons (1-13) were detected.

Previously described mutations were even only identified in 50\% of the PHP-Ia patients [7]. This is in accordance with prior data from patients with $\mathrm{AHO}$, who presented in $85 \%$ of the cases a reduction of Gsa protein activity, whereas only $50 \%$ of these patients showed GNAS coding mutations [10]. One explanation could be the presence of a genetic defect outside the coding region of the GNAS gene, probably in the promoter region or in other regulatory regions leading to Gs $\alpha$ deficiency.

In patients presenting an $\mathrm{AHO}$ phenotype a broad epigenetic GNAS defect without a GNAS coding mutation was detected $[17,19]$. Therefore, we performed GNAS methylation studies in the 4 patients with reduced Gsa protein activity. In our analysis, although a slight tendency of reduced methylation in short stature patients compared to control was observed, it was not statistically significant. In our opinion, these findings cannot completely explain the reduction of Gsa activity in our patients. As we focused on regions which were previously described to be important in GNAS epigenetics [18], we cannot exclude that other methylation changes outside of the analysed regions could be associated with the loss of Gsa activity in our patients.

We hypothesize that patients with short stature and disproportionate short metacarpals and a reduction of 
the Gsa protein activity could be part of the wide range of the different types of PHP/PPHP and a genetic overlap may exist. This hypothesis is supported by the fact that until now Gsa hypofunction has been reported to different extents in patients with PHP-Ia, PHP-Ib or PPHP $[17,25,26]$. Many authors demand a new classification of the different groups of PHP [18], which is also supported by Fernandez-Rebollo et al. [33] who reported a patient with a clinical diagnosis of PHP-Ia, reduced Gsa activity, no coding mutation on Gsa exons (1-13), and a loss of methylation in exon $\mathrm{A} / \mathrm{B}$. These investigations for the first time ruled out a large intragenic deletion within the GNAS locus, involving not only Gsa coding exons, but also exon A/B located upstream of Gsa [33]. By this complex deletion, the methylation defect on exon $\mathrm{A} / \mathrm{B}$, the clinical AHO phenotype, and the reduced Gsa function could be explained indicating an overlap between molecular and clinical features of the different types of PHP/PPHP. Such complex genetic changes in the GNAS cluster could also be involved in our patients and need to be further investigated.

An unexpected finding was that we identified Gsa hypofunction in 1 female with TS (No. 15) (table 2). In patients with TS, SHOX haploinsufficiency is thought to explain short metacarpals [34]. The disproportionate shortening of the metacarpals in this individual was not as severe as it was in patient No. 16 with normal Gsa function (table 2). Therefore, we hypothesize that SHOX haploinsufficiency and Gsa hypofunction are not additively causing short metacarpals and presumably both signalling pathways lead to one unknown mechanism. This theory must however be confirmed by experimental evidence.

To summarize, we describe a distinct clinical phenotype characterized by short stature and pronounced shortening of the 4th and 5 th metacarpal length in relation to their height. We hypothesize that these patients could be part of the wide variety of PHP/PPHP, because Gsa hypofunction was detected in $25 \%$ of the patients. Analysis of the 1-13 coding exons of the GNAS gene and epigenetic analysis do not reveal any mutations or significant epigenetic changes in these patients. However, we think it is worthwhile analysing in patients with short stature and disproportionate metacarpal shortening the Gsa protein activity, GNAS gene, epigenetic alteration, and intragenic deletion in the GNAS cluster to further elucidate the phenotype and genotype of Gsa dysfunction.

\section{Acknowledgements}

I.M.I. has received grant support (November 1, 2005 to September 30, 2007) from Novo Nordisk, Bagsvaerd, Denmark.

\section{References}

1 Albright F, Burnett CH, Smith CH, Parson W: Pseudohypoparathyroidism: an example of 'Seabright-Bantam syndrome.' Endocrinology 1942;30:922-932.

2 Weinstein LS, Yu S, Warner DR, Liu J: Endocrine manifestation of stimulatory $\mathrm{G}$ protein a subunit mutations and the role of genomic imprinting. Endocr Rev 2001;22:675705.

3 Mantovani G, Maghnie M, Weber G, De Menis E, Brunelli V, Cappa M, Loli P, BeckPeccoz P, Spada A: Growth hormone-releasing hormone resistance in pseudohypoparathyroidism type Ia: new evidence for imprinting of the Gsa gene. J Clin Endocrinol Metab 2003;88:4070-4074.

4 Campbell R, Gosden CM, Bonthron DT: Parental origin of transcription from the human GNAS1 gene. J Med Genet 1994;31:607-614.

5 Hayward BE, Barlier A, Korbonits M, Grossman $A B$, Jacquet $P$, Enjalbert A, Bonthron DT: Imprinting of the Gsa gene GNAS1 in the pathogenesis of acromegaly. J Clin Invest 2001;107:R31-R36.
-6 Mantovani G, Ballare E, Giammona E, BeckPeccoz P, Spada A: The Gsa gene: predominant maternal origin of transcription in human thyroid gland and gonads. J Clin Endocrinol Metab 2002;87:4736-4740.

7 Ahrens W, Hiort O, Staedt P, Kirschner T, Marschke C, Kruse K: Analysis of the GNAS1 gene in Albright's hereditary osteodystrophy. J Clin Endocrinol Metab 2001;86:4630-4634.

-8 Mantovani G, Romoli R, Weber G, Brunelli V, de Menis E, Beccio S, Beck-Peccoz P, Spada A: Mutational analysis of GNAS1 in patients with pseudohypoparathyroidism: identification of two novel mutations. J Clin Endocrinol Metab 2000;85:4243-4248.

-9 Levine MA, Downs RW Jr, Singer M, Marx SJ, Aurbach GD, Spiegel AM: Deficient activity of guanine nucleotide regulatory protein in erythrocytes from patients with pseudohypoparathyroidism. Biochem Biophys Res Commun 1980;94:1319-1324.

$\rightarrow 10$ Ahrens W, Hiort O: Determination of Gsa protein activity in Albright's hereditary osteodystrophy. J Pediatr Endocrinol Metab 2006; 19:647-651.
11 Weiss U, Ischia R, Eder S, Lovisetti-Scamihorn P, Bauer R, Fischer-Colbrie R: Neuroendocrine secretory protein 55 (NESP55): alternative splicing onto transcripts of the GNAS gene and posttranslational processing of maternally protein. Neuroendocrinology 2000; 71:177-186.

12 Kehlenbach RH, Matthey J, Huttner WB: XLas is a new type of G protein. Nature 1994; 372:804-809.

13 Hayward BE, Moran V, Strain L, Bonthron DT: Bidirectional imprinting of a single gene: GNAS1 encodes maternally, paternally and biallelically derived proteins. Proc Natl Acad Sci USA 1998;95:15475-15478.

14 Hayward BE, Bonthron DT: An imprinted antisense transcript at the human GNAS1 locus. Hum Mol Genet 2000;9:835-841.

15 Liu J, Nealon JG, Weinstein LS: Distinct patterns of abnormal GNAS imprinting in familial and sporadic pseudohypoparathyroidism type IB. Hum Mol Genet 2005;14: 95-102. 
16 Bastepe M, Fröhlich LF, Linglart A, Abu-Zahra HS, Tojo K, Ward LM, Jüppner H: Deletion of the NESP55 differentially methylated region causes loss of maternal GNAS imprints and pseudohypoparathyroidism type Ib. Nat Genet 2005;37:25-27.

-17 De Nanclares GP, Fernández-Rebollo E, Santin I, García-Cuartero B, Gaztambide S, Menéndez E, Morales MJ, Pombo M, Bilbao JR, Barros F, Zazo N, Ahrens W, Jüppner H, Hiort $\mathrm{O}$, Castaño L, Bastepe M: Epigenetic defects of GNAS in patients with pseudohypoparathyroidism and mild features of Albright's hereditary osteodystrophy. J Clin Endocrinol Metab 2007;93:661665.

18 Mantovani G, de Sanctis L, Barbieri AM, Elli FM, Bollati V, Vaira V, Labarile P, Bondioni S, Peverelli E, Lania AG, Beck-Peccoz P, Spada A: Pseudohypoparathyroidism and GNAS epigenetic defects: clinical evaluation of Albright's hereditary osteodystrophy and molecular analysis in 40 patients. J Clin Endocrinol Metab 2010;95:651-658.

19 Mariot V, Maupetit-Méhouas S, Sinding C, Kottler ML, Linglart A: A maternal epimutation of GNAS leads to Albright osteodystrophy and parathyroid hormone resistance. J Clin Endocrinol Metab 2008;93:661-665.

20 Reinken L, van Oost G: Longitudinale Körperentwicklung gesunder Kinder von 0 bis 18 Jahren. Klin Paediatr 1992;204:129-133.

-21 Gerver WJ, Drayer NM, Schaafsma W: Reference values of anthropometric measurements in Dutch children. The Oosterwolde Study. Acta Paediatr Scand 1989;78:307-313.
22 Fredriks AM, van Buuren S, van Heel WJ, Dijkman-Neerincx RH, Verloove-Vanhorick SP, Wit JM: Nationwide age references for sitting height, leg length, and sitting height/ height ratio, and their diagnostic value for disproportionate growth disorders. Arch Dis Child 2005;90:807-812.

23 Greulich WW, Pyle SI: Radiographic Atlas of Skeletal Development of the Hand and Wrist. Stanford, Stanford University Press, 1959.

24 Thompson W, Kelvin L: Radiologic anthropometry of the hand; in Poznanski AK (ed): The Hand in Radiologic Diagnosis with Gamuts and Pattern Profiles, ed 2. Philadelphia, Saunders, 1984, pp 34-35.

25 Freson K, Thys C, Wittevrongel C, Proesmans W, Hoylaerts MF, Vermylen J, Van Geet C: Pseudohypoparathyroidism type Ib with disturbed imprinting in the GNAS1 cluster and Gs $\alpha$ deficiency in platelets. Hum Mol Genet 2002;11:2741-2750.

26 Freson K, Izzi B, Labarque V, Van Helvoirt M, Thys C, Wittevrongel C, Bex M, Bouillon R, Godefroid N, Proesmans W, de Zegher F, Jaeken J, Van Geet C: GNAS defects identified by stimulatory $G$ protein a subunit signalling studies in platelets. J Clin Endocrinol Metab 2008;93:4851-4859.

27 Mantovani G, Romoli R, Weber G, Brunelli V, de Menis E, Beccio S, Beck-Peccoz P, Spada A: Mutational analysis of GNAS1 in patients with pseudohypoparathyroidism: identification of two novel mutations. J Clin Endocrinol Metab 2000;85:4243-4248.

28 Weber M, Davies JJ, Wittig D, Oakeley EJ, Haase M, Lam WL, Schübeler D: Chromosome-wide and promoter-specific analyses identify sites of differential DNA methylation in normal and transformed human cells. Nat Genet 2005;37:853-862.
29 Mantovani G, Bondioni S, Linglart A, Maghnie $M$, Cisternino $M$, Corbetta S, Lania AG, Beck-Peccoz P, Spada A: Genetic analysis and evaluation of resistance to thyrothropin and growth hormone-releasing hormone in pseudohypoparathyroidism type Ib. J Clin Endocrinol Metab 2007;92:3738-3742.

30 Laurencikas E, Sävendahl L, Jorulf H: Metacarpophalangeal pattern profile analysis: useful diagnostic tool for differentiating between dyschondrosteosis, Turner syndrome, and hypochondroplasia. Acta Radiol 2006;47: 518-524.

31 Temtamy SA, Aglan MS: Brachydactyly. Orphanet J Rare Dis 2008;3:15.

32 Izzi B, Francois I, Labarque V, Thys C, Wittevrongel C, Devriendt K, Legius E, Van den Bruel A, D’Hooghe M, Lambrechts D, de Zegher F, Van Geet C, Freson K: Methylation defect in imprinted genes detected in patients with an Albright's hereditary osteodystrophy like phenotype and platelet Gs hypofunction. PloS One 2012;7:e38579.

33 Fernandez-Rebollo E, García-Cuartero B, Garin I, Largo C, Martínez F, Garcia-Lacalle C, Castaño L, Bastepe M, Pérez de Nanclares G: Intragenic GNAS deletion involving exon $\mathrm{A} / \mathrm{B}$ in pseudohypoparathyroidism type $1 \mathrm{~A}$ resulting in an apparent loss of exon A/B methylation: potential for misdiagnosis of pseudohypoparathyroidism type 1B. J Clin Endocrinol Metab 2010;95:765771.

34 Hjerrild BE: Turner syndrome and clinical treatment. Br Med Bull 2008;86:77-93. 